\title{
Processing of a Continuous Ceramic Fiber/Iron Alloy Composite *1
}

\author{
Hidekazu Sueyoshi ${ }^{1}$, Tomohito Maruno ${ }^{1 * 2}$, Koichi Yamamoto ${ }^{1 * 3}$, Yoshihiro Hirata ${ }^{2}$, \\ Soichiro Sameshima ${ }^{2}$, Shigeru Uchida ${ }^{3}$, Shuichi Hamauzu ${ }^{4}$ and Sumihiko Kurita ${ }^{5}$ \\ ${ }^{1}$ Department of Mechanical Engineering, Faculty of Engineering, Kagoshima University, Kagoshima 890-0065, Japan \\ ${ }^{2}$ Department of Applied Chemistry and Chemical Engineering, Faculty of Engineering, \\ Kagoshima University, Kagoshima 890-0065, Japan \\ ${ }^{3}$ Steel Research Laboratory, Nippon Steel Corporation, Futtsu 293-8511, Japan \\ ${ }^{4}$ Plant and Machinery Division, Mishima Kosan Co., Ltd., Kitakyushu 800-0211, Japan \\ ${ }^{5}$ Research and Development Division, Koransha Co.,Ltd., Arita 844-8601, Japan
}

Processing of a continuous ceramic fiber/iron alloy composite by powder metallurgy was investigated. The preparation of continuous ceramic fiber/iron alloy composite is feasible by hot isostatic pressing of a laminate of iron alloy powder sheets, prepared from a doctor blade method, and continuous ceramic fiber sheets. It is necessary to choose suitable temperature and pressure which enable iron alloy to penetrate into ceramic yarn through the small openings between the fibers. The continuous ceramic fiber/iron alloy composite in which fibers are uniformly dispersed can be produced by choosing an appropriate combination of the thickness of iron alloy powder sheet and the number of continuous ceramic fiber sheet.

(Received December 12, 2001; Accepted February 26, 2002)

Keywords: continuous ceramic fiber, iron alloy, composite, processing, powder metallurgy, hot isostatic press

\section{Introduction}

Continuous ceramic fiber reinforced metal is a metal matrix composite reinforced with high-strength continuous ceramic fiber. Aluminum is light and has a low melting point. Therefore, several aluminum matrix composites have been developed. The fusion-solidification method has been generally used as the production method. However, it has been reported that wetting of the liquid metal on the surface of the ceramic fiber and the reaction at the fiber-liquid metal interface affect the mechanical properties of the composite. ${ }^{1-3)}$ As an improvement on wettability, some coating treatments on ceramic fiber have been reported. ${ }^{4-6)}$

On the other hand, few studies have been conducted so far on the composite made from titanium or iron which has a high melting point. This is because the reaction at the fiberliquid metal interface is activated and damage to the fiber is accelerated as the melting point of matrix metal increases.7) Therefore, a new type of production process is required for the titanium matrix and iron matrix composites. Recently, a production method with electron beam vapor deposition was reported for titanium matrix composite. ${ }^{8,9)}$ However, it is difficult to use this method for a fine fiber. Furthermore, production by this method is very expensive. On the other hand, there have been few reports regarding iron matrix composite.

We examined the processing of continuous ceramic fiber/iron alloy composite by powder metallurgy. Powder metallurgy is highly suitable for retarding damage to ceramic fiber because the sintering temperature is very low as compared with the melting point. Commercially, continuous ce-

\footnotetext{
${ }^{* 1}$ This Paper was Originally Published in Japanese in J. Japan Inst. Metals, 65 (2001) 961.

${ }^{* 2}$ Graduate Student, Kagoshima University. Present address: Toshiba Co., Ltd.

${ }^{* 3}$ Graduate Student, Kagoshima University. Present address: Mitsui Zosen Co., Ltd.
}

ramic fiber is supplied as a yarn consisting of several hundred filaments with an average diameter of about $10 \mu \mathrm{m}$ or as a woven fabric. Therefore, in powder metallurgy processing, the manner of penetration of iron alloys into ceramic yarn and the manner of dispersion of ceramic filaments are of great importance. In the present study, iron alloy powder sheets prepared by the doctor blade method and continuous ceramic fiber sheets were alternately laminated in various ratios, followed by hot isostatic pressing. As a result, a composite in which ceramic filaments were uniformly dispersed was obtained. In this paper, the process for preparing the composite is explained in detail.

\section{Experimental Procedure}

Figure 1 shows a schematic processing diagram of the composite. Woven alumina fabrics (Mitsui Mining Material Co., Ltd.: Almax; crystal phase: $\alpha \mathrm{Al}_{2} \mathrm{O}_{3}$; purity: $\mathrm{Al}_{2} \mathrm{O}_{3}>99.5$ mass $\%$; true density: $3.6 \mathrm{Mg} / \mathrm{m}^{3}$; filament diameter: $10 \mu \mathrm{m}$; the number of filaments; 1000 filaments/yarn; Young's modulus: $323 \mathrm{GPa}$; tensile strength: $1.76 \mathrm{GPa}$; thermal expansion coefficient: $8 \times 10^{-6} \mathrm{~K}^{-1}$ ) were used as the starting continuous ceramic fiber. Unidirectional alumina fiber sheets were prepared by removing most of the traverse yarns from the woven fabrics. High-speed steel (HSS) powder (Mitsubishi Metal Co., Ltd.: MIREX; mean particle size: $13.4 \mu \mathrm{m}$; true density: $7.93 \mathrm{Mg} / \mathrm{m}^{3}$ ) was used as the starting iron alloy. The chemical composition of HSS powder is listed in Table1. An ethylene Glycol suspension of HSS powder was prepared by adding starch (binder). HSS powder sheets of various thicknesses were prepared using a doctor blade (Tsugawa Seiki Seisakusho: DP-100).

Unidirectional alumina fiber sheets and HSS powder sheets were alternately laminated in the different ratio. The alumina fiber sheet/HSS powder sheet laminated sample was placed 


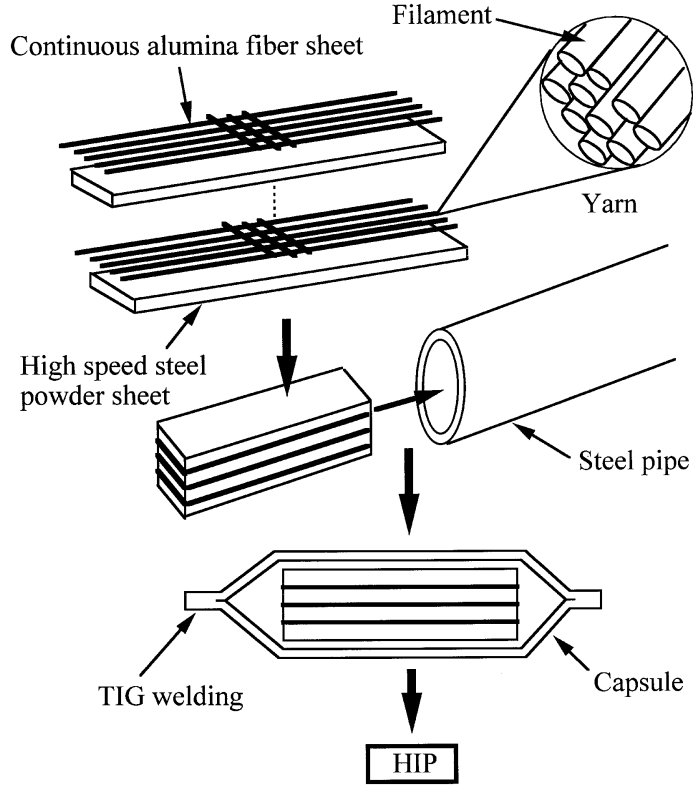

Fig. 1 Schematic processing diagram of the composite.

Table 1 Chemical composition of high-speed steel powder (mass\%).

\begin{tabular}{cccccccccc}
\hline $\mathrm{Fe}$ & $\mathrm{C}$ & $\mathrm{W}$ & $\mathrm{Mo}$ & $\mathrm{Cr}$ & $\mathrm{V}$ & $\mathrm{Mn}$ & $\mathrm{Si}$ & $\mathrm{P}$ & $\mathrm{S}$ \\
\hline 81.91 & 0.85 & 6.01 & 4.88 & 4.03 & 1.94 & 0.12 & 0.23 & 0.022 & 0.009 \\
\hline
\end{tabular}

inside a steel pipe welded at one end, which was degassed at $823 \mathrm{~K}$ in vacuum and then sealed in vacuum. Differential thermal analysis revealed that ethylene Glycol is decomposed by heating at about $370 \mathrm{~K}$ and the sizing agent (epoxy resin) for alumina fiber is burnt out by heating at about $770 \mathrm{~K}$. The degassing conditions were set on the basis of these results. The steel capsule obtained was hot isostatically pressed (HIPed) under various conditions of temperature and pressure. Microstructures of cross and longitudinal sections of the HIPed composite were examined using an electron probe microanalyzer (EPMA).

\section{Results and Discussion}

HSS powder sheets and unidirectional alumina fiber sheets were alternately laminated in the ratio $1: 1$, followed by HIPing by the process in which heating precede pressing. Figure 2 shows a schematic diagram of the HIP process. The laminated sample was heated at the rate of $10 \mathrm{~K} / \mathrm{min}$, and then hold at $1273 \mathrm{~K}$. Upon reaching the temperature of $1273 \mathrm{~K}$, pressing was carried out immediately. The laminated sample was HIPed at $1273 \mathrm{~K}$ for various times at the pressure of 98.1 MPa. Both temperature and pressure decreased simultaneously after HIPing. Figure 3 shows a secondary electron (SE) image of the cross section of the composite obtained by HIPing at $1273 \mathrm{~K}$ for $0.5 \mathrm{~h}$ at the pressure of $98.1 \mathrm{MPa}$. No sintering of HSS powder was achieved, resulting in the presence of voids. Figure 4 shows an SE image of the cross section of the composite obtained by HIPing at $1273 \mathrm{~K}$ for $2 \mathrm{~h}$ at the pressure of 98.1 MPa. Sintering of HSS powder with no damage to alumina fibers was achieved. Thus HIPing at $1273 \mathrm{~K}$ for $2 \mathrm{~h}$ at the pressure of $98.1 \mathrm{MPa}$ is suitable for sintering HSS powder.

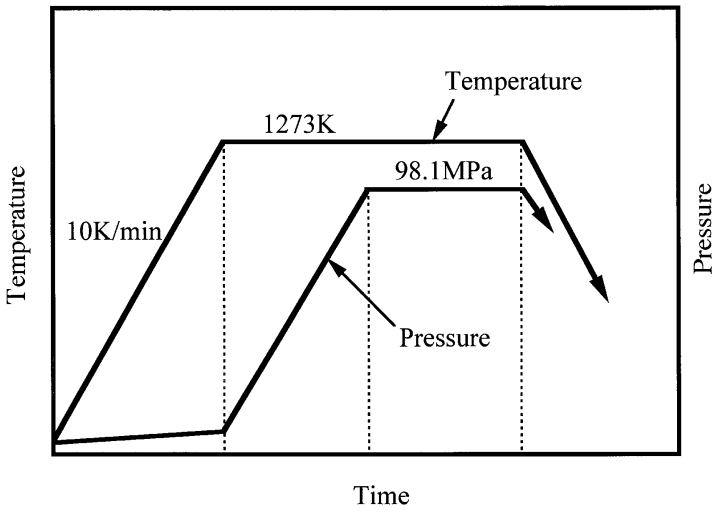

Fig. 2 Schematic diagram of HIP process.

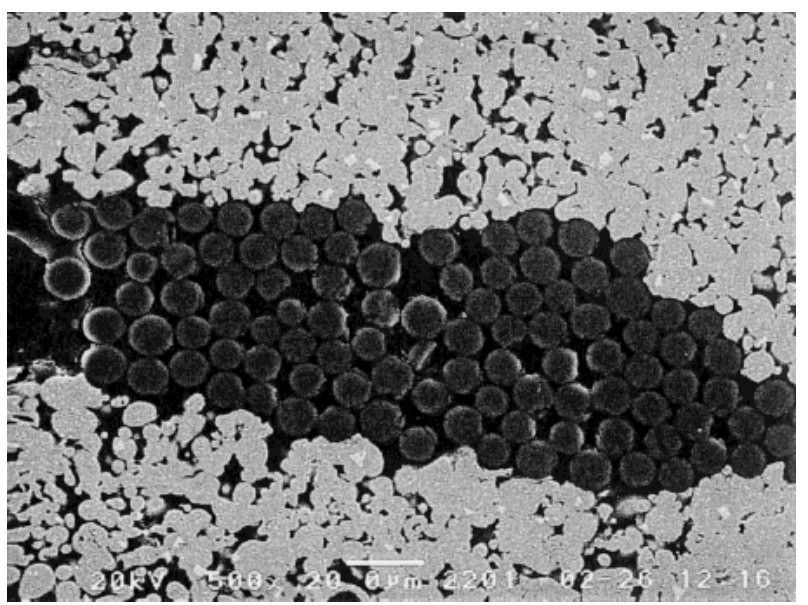

Fig. 3 Secondary electron image of the cross section of the composite obtained by HIPing at $1273 \mathrm{~K}$ for $0.5 \mathrm{~h}$ under the pressure of $98.1 \mathrm{MPa}$.

However, as shown in Figs. 3 and 4, no penetration of HSS powder into alumina yarn was achieved, resulting in residual open spaces in the alumina yarn. Because the arrangement of alumina fibers is identical to a close-packed sequence, HSS powder cannot easily overcome strong mutual pushing forces between alumina fibers to penetrate into alumina yarn. Although mutual pushing forces between alumina fibers are weak in the early stage of pressing at low pressure, no penetration of HSS powder into alumina yarn was achieved. This is because HSS powder does not easily flow plastically under low pressure.

To examine the effect of the HIPing time on the penetration behavior of HSS powder into alumina yarn, HIPing time was lengthened to $4 \mathrm{~h}$. Figure 5 shows an SE image of the cross section of the composite obtained. However, no penetration of HSS powder into alumina yarn was achieved. On the other hand, damage to alumina fibers, such as sintering, was observed. This suggests that penetration of HSS powder into alumina yarn is independent of HIPing time, but dependent on HIPing temperature and pressure.

HIPing was carried out at high temperature by the pressing process which enables penetration of HSS powder into alumina yarn. Figure 6 shows a schematic diagram of the HIP process. First the laminated sample was heated to the temperature of $1473 \mathrm{~K}$ to improve the plasticity of HSS powder. However, penetration of HSS powder into alumina yarn 


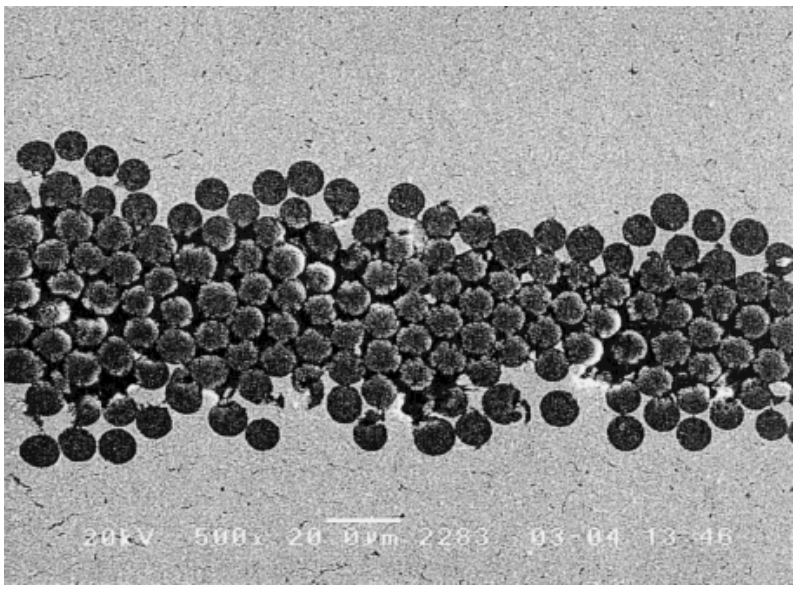

Fig. 4 Secondary electron image of the cross section of the composite obtained by HIPing at $1273 \mathrm{~K}$ for $2 \mathrm{~h}$ under the pressure of $98.1 \mathrm{MPa}$.

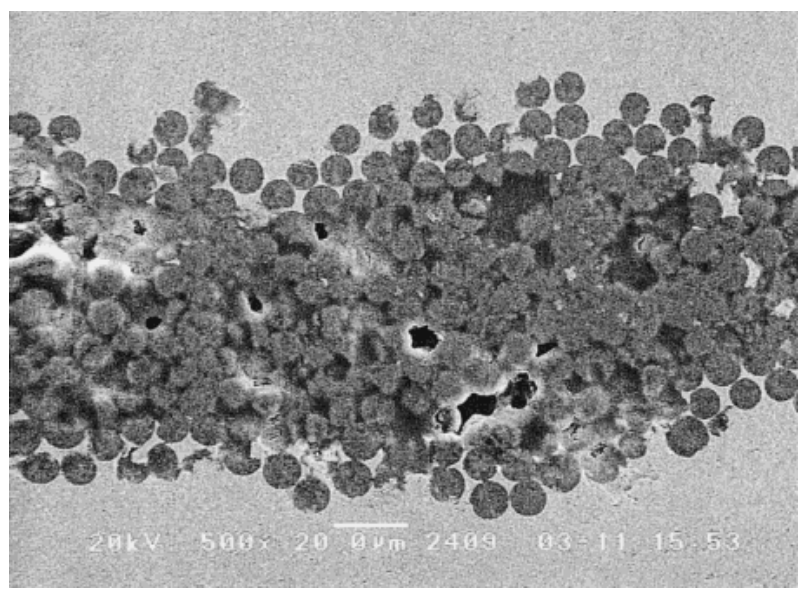

Fig. 5 Secondary electron image of the cross section of the composite obtained by HIPing at $1273 \mathrm{~K}$ for $4 \mathrm{~h}$ under the pressure of $98.1 \mathrm{MPa}$.

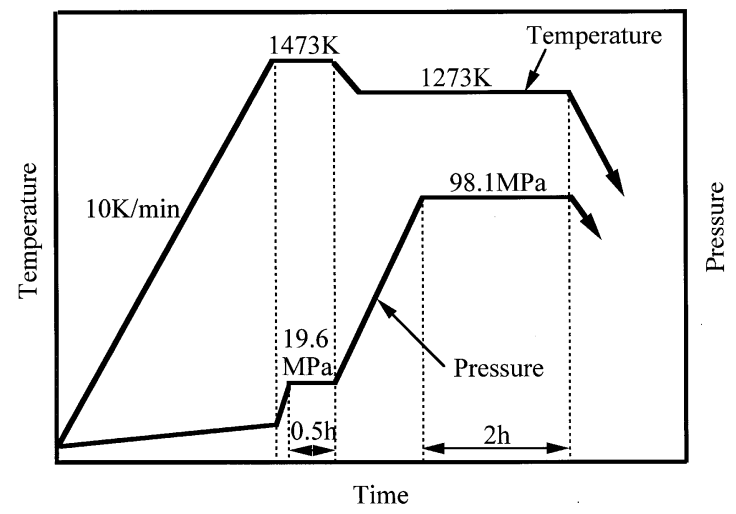

Fig. 6 Schematic diagram of the two-stage HIP process.

may be prevented by the strong mutual pushing forces between alumina fibers when pressing pressure is too high. Conversely, when pressing pressure is too low, it is impossible for HSS powder to penetrate into alumina yarn because HSS powder is not deformed plastically under low pressure. Thus the pressure for HIPing at $1473 \mathrm{~K}$ was set at $19.6 \mathrm{MPa}$. Also, HIPing time was shortened to $0.5 \mathrm{~h}$ to prevent damage to alumina fibers at high temperature. After this first HIPing stage,

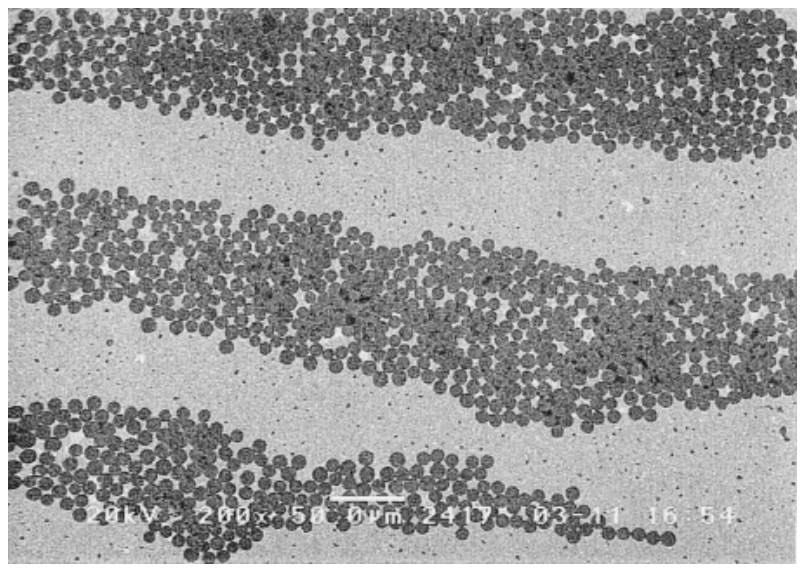

Fig. 7 Secondary electron image of the cross section of the composite obtained by HIPing under the condition shown in Fig. 6.

the second HIPing stage was carried out at a lower temperature $(1273 \mathrm{~K})$ for $2 \mathrm{~h}$ under a higher pressure $(98.1 \mathrm{MPa})$. The purposes of the first stage and second stage of HIPing are to penetrate HSS powder into the alumina yarn and to sinter HSS powder without damage to alumina fibers, respectively. Therefore, the conditions in the second HIPing stage were the same as those for the sample shown in Fig. 4 (1273 K, 98.1 MPa, $2 \mathrm{~h}$ ).

Figure 7 shows an SE image of the cross section of the composite obtained by HIPing under the conditions shown in Fig. 6. Penetration of HSS powder into alumna yarn was achieved. This suggests that HSS powder penetrated into alumina yarn during the first HIPing stage. To clarify this behavior, the microstructure of the sample was examined by EPMA.

As shown in Figs. 4 and 7, fiberless areas remained between alumina yarns. Figure 8 shows SE images of this area ((a) the composite obtained by HIPing at $1273 \mathrm{~K}$; (b) the composite obtained by two-stage HIP process (Fig. 6). Figure 9 shows the result of energy dispersion X-ray analysis on the white phase in Fig. 8(b). The $\mathrm{W}$ peak is the highest. The peak of Mo is intermediate, and small peaks of $\mathrm{Cr}$ and $\mathrm{V}$ are also noticed. Based on these results, the white phase may be double carbides consisting mainly of $\mathrm{W}$, Mo, $\mathrm{Cr}$ and $\mathrm{V} .{ }^{10)} \mathrm{As}$ shown in Fig. 8, the two-stage HIP process increased the size of double-carbide particles, but reduced the number of particles.

Figure 10 shows an SE image of the interior of the alumina yarn in Fig. 7. Double carbides were large in size and heterogeneous in shape as compared with those shown in Fig. 8(b). Most of the double carbides precipitated around alumina fibers. Based on these results, the behavior of HSS powder during the two-stage HIP process may be considered as follows. Double carbides redissolved into austenite at $1473 \mathrm{~K}$. This is inferred from the fact that the quenching temperature of HSS is normally about $1473 \mathrm{~K} .{ }^{10)}$ With the redissolution of double carbides, the dominant factor governing the strength of HSS powder changes from precipitation hardening to solution hardening. The HIPing temperature $(1473 \mathrm{~K})$ was near the melting point of HSS. Because HSS powder is softened for the two reasons stated above, penetration of HSS powder into alumina yarn was achieved even under the pressure of 19.6 MPa. Large double carbides precipitated at the alumina 

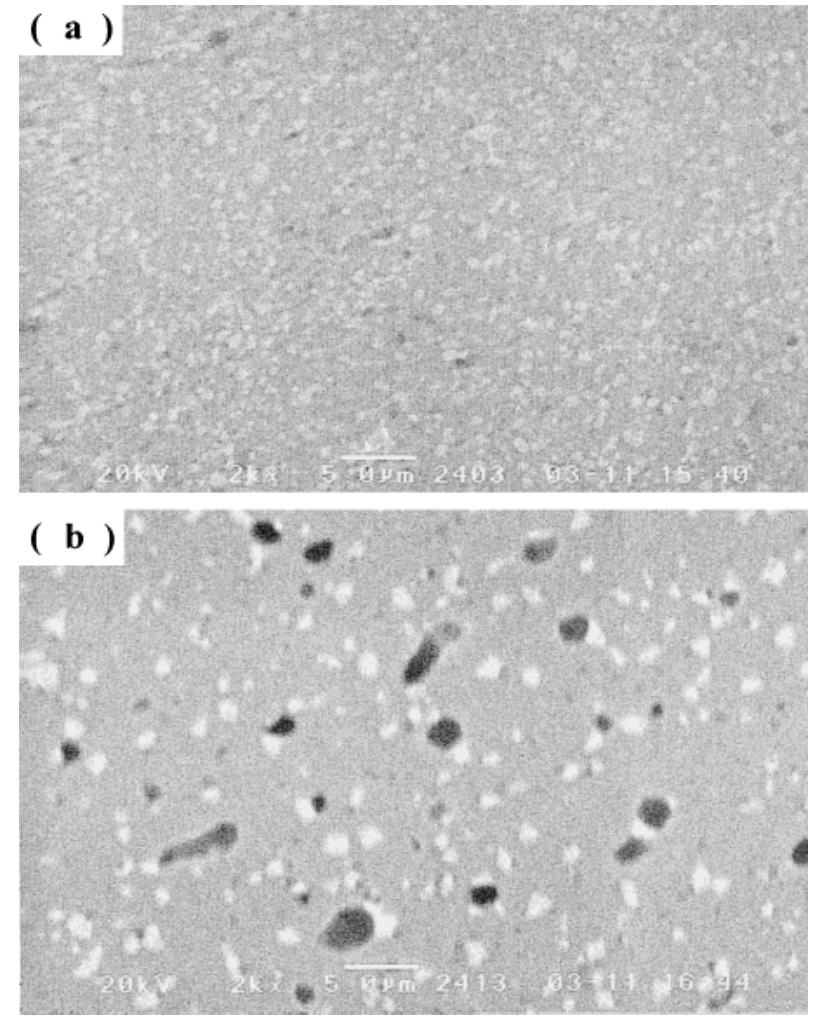

Fig. 8 Secondary electron images of the area sintered only high-speed steel powders. (a) the composite shown in Fig. 4, (b) the composite shown in Fig. 7.

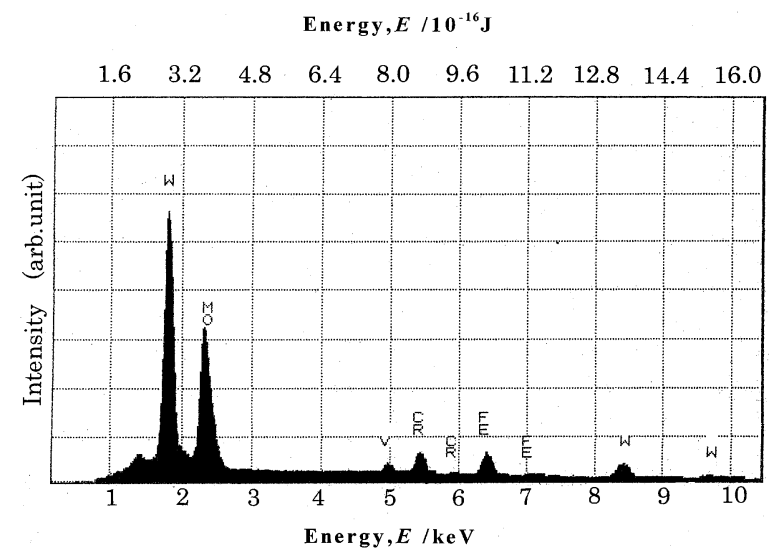

Fig. 9 EDX analysis on the white phase in Fig. 8(b).

fiber-HSS interface and the grain boundaries during cooling after HIPing.

As mentioned above, two-stage HIPing of the sample of alumina fiber sheets and HSS powder sheets alternately laminated in the ratio 1:1 resulted in a uniform dispersion of alumina fibers in yarn. However, fiberless areas remained between alumina yarns. This was because the HSS powder sheet was too thick, that is, the amount of HSS powder was too great. Therefore, we discussed the appropriate combination of alumina fiber sheets and HSS powder sheets. Based on the mass and density of the alumina fiber sheet, the volume of the alumina fiber sheet of $21 \mathrm{~mm}$ width and $40 \mathrm{~mm}$ length is $4.17 \times 10^{-8} \mathrm{~m}^{3}$. The volume per unit thickness $(\mu \mathrm{m})$ of such a

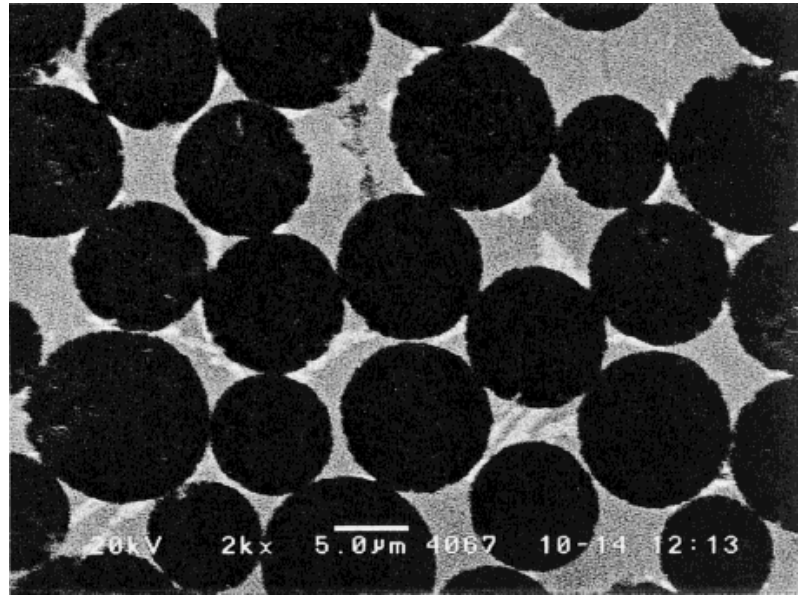

Fig. 10 Secondary electron image of the area composed of alumina filaments and high-speed steel.

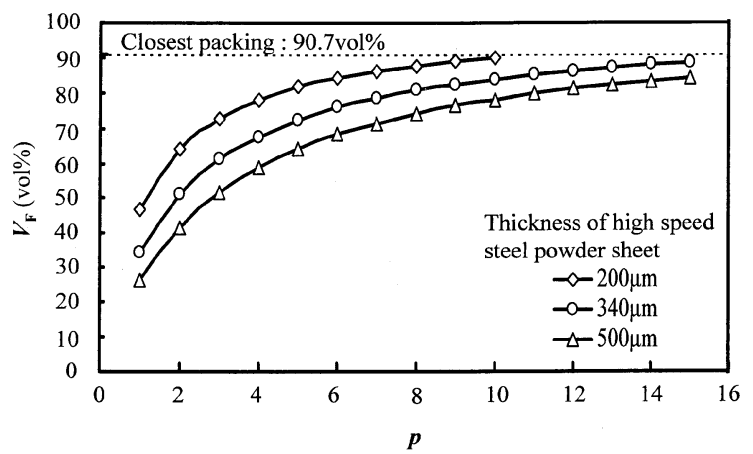

Fig. 11 Relation between the volume fraction of continuous alumina fiber, $V_{\mathrm{F}}$, and the number of continuous alumina fiber sheet, $p$.

HSS powder sheet is $2.33 \times 10^{-10} \mathrm{~m}^{3}$. Using these values, the volume fraction of alumina fibers in the composite is given by the following equation.

$$
V_{\mathrm{F}}=417 p /(417 p+2.33 d) \times 100
$$

Where $V_{\mathrm{F}}$ is the volume fraction of alumina fibers (vol\%), $p$ is the number of alumina fiber sheets, and $d$ is the thickness of one HSS powder sheet $(\mu \mathrm{m})$. Figure 11 shows the relationship between the volume fraction of alumina fibers and the number of alumina fiber sheets. Assuming that the arrangement of alumina fibers $(10 \mu \mathrm{m}$ in diameter $)$ is identical to the closepacked sequence, $V_{\mathrm{F}}$ is $91 \mathrm{vol} \%$. In Fig. 11, the dotted line shows this value. However, as shown in Fig. 10, no closepacked sequences were observed in the composite obtained. Based on the measurement of the area of alumina fibers, the volume fraction of alumina fibers in the uniformly dispersed area shown in Fig. 10 was 82 vol\%.

Figure 12 shows an SE image of the cross section of the composite obtained by HIPing the sample, in which the ratio of alumina fiber sheets to HSS powder sheets of $500 \mu \mathrm{m}$ thickness is $4: 1$, under the conditions shown in Fig. 6. Penetration of HSS powder into alumina yarn was achieved. However, fiberless area remained between the alumina yarns. Figure 11 indicates that twelve alumina fiber sheets are necessary with an HSS powder sheet of $500 \mu \mathrm{m}$ thickness to form a composite with the volume fraction of $82 \mathrm{vol} \%$. As the number of alumina fiber sheets increases, the distance from the out- 


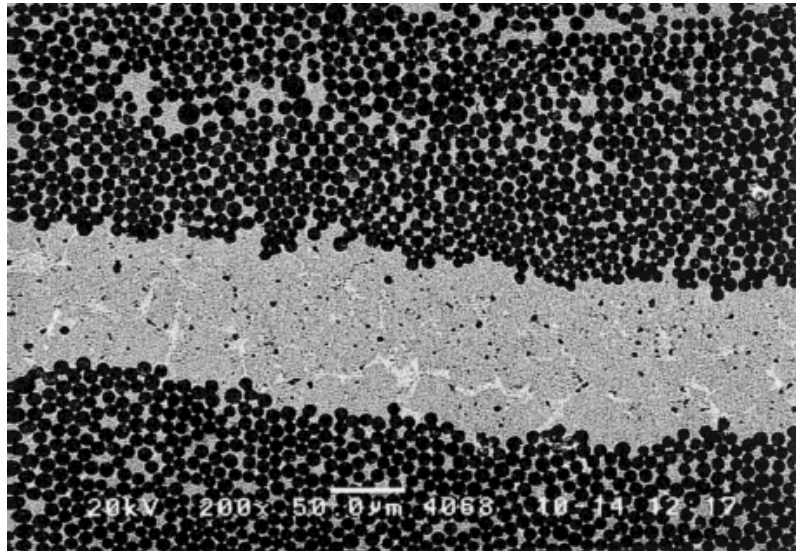

Fig. 12 Secondary electron image of the cross section of the composite obtained by HIPing the laminate which the ratio of continuous alumina fiber sheet to high-speed steel powder sheet of $500 \mu \mathrm{m}$ thickness is in the ratio 1:4 under the condition shown in Fig. 6.
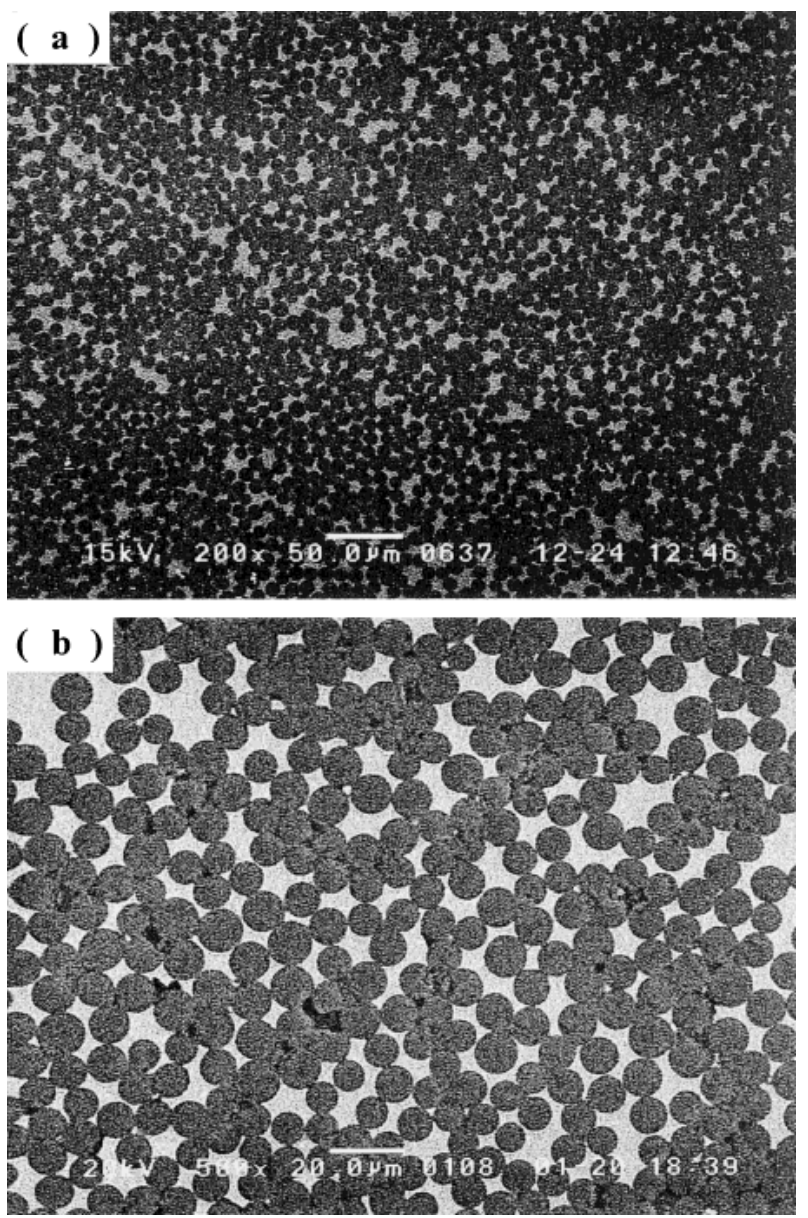

Fig. 13 Secondary electron images of the cross section of the composite obtained by HIPing the laminate which the ratio of continuous alumina fiber sheet to high-speed steel powder sheet of $200 \mu \mathrm{m}$ thickness is in the ratio 1:5 under the condition shown in Fig. 6. (a) wide view, (b) magnification of (a).

side of yarn to the center of alumina fiber sheets, that is, the distance of HSS powder migration, becomes longer. For an HSS powder sheet of $500 \mu \mathrm{m}$ thickness, the migration distance is equivalent to the thickness of six alumina fiber sheets. Therefore, one can predict that HSS powder cannot reach the center of twelve alumina fiber sheets. Conversely, because a

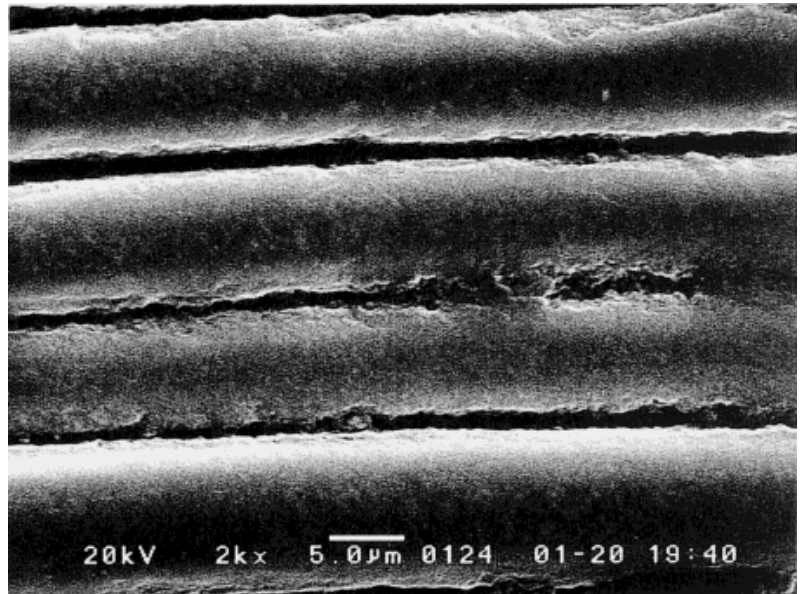

Fig. 14 Secondary electron image of the longitudinal section of the composite shown in Fig. 13.

decrease in the thickness of the HSS powder sheet enables a decrease in the number of alumina fiber sheets, HSS powder may readily reach the center of alumina fiber sheets.

The sample in which the ratio of alumina fiber sheets to HSS powder sheets of $200 \mu \mathrm{m}$ thickness is 5:1 (See Fig. 11), which give the volume fraction of about $82 \mathrm{vol} \%$, was HIPed under the conditions shown in Fig. 6. Figure 13 shows SE images of the cross section of the composite obtained. Uniform dispersion of alumina fibers in HSS matrix was achieved. The fiberless area was absent. Figure 14 shows an SE image of the longitudinal section of the composite shown in Fig. 13. Alumina fibers were parallel with each other. Also there was no damage to the alumina fiber. Thus, good composites could be prepared by the two-stage HIP process shown in Fig. 6 . The composite obtained may be regarded as a ceramic matrix composite rather than a metal matrix composite, because the volume fraction of ceramic fibers is $82 \mathrm{vol} \%$.

\section{Conclusions}

Processing of continuous ceramic fiber/iron alloy composite by powder metallurgy was investigated. The following conclusions were obtained.

(1) The preparation of a continuous ceramic fiber/iron alloy composite is feasible by hot isostatic pressing of a lamination of iron alloy powder sheets, prepared by a doctor blade method, and continuous ceramic fiber sheets.

(2) It is necessary to choose suitable conditions of temperature and pressure which enable iron alloy to penetrate into ceramic yarn through the small openings between the fibers.

(3) The continuous ceramic fiber/iron alloy composite in which fibers are uniformly dispersed can be produced by choosing an appropriate combination of the thickness of the iron alloy powder sheet and the number of continuous ceramic fiber sheets.

\section{REFERENCES}

1) Y. Kimura, Y. Mishima, S. Umekawa and T. Suzuki: J. Mater. Sci. 19 (1984) 3107-3114.

2) H. Liu, U. Madaleno, T. Shinoda, Y. Mishina and T. Suzuki: J. Mater. Sci. 25 (1990) 4247-4254. 
3) P. B. Maxwell, G. P. Martins, D. L. Olson and G. R. Edwards: Metall. Mater. Trans. B 21B (1990) 475-485.

4) S. Abraham, B. C. Pai and K. G. Satyanarayana: J. Mater. Sci. 27 (1992) 3479-3486.

5) S. G. Wrrier, C. A. Blue and R. Y. Lin: J. Mater. Sci. 28 (1993) 760-768.

6) K. K. Lee, C. S. Kang and D. J. Lee: J. Japan Inst. Metals 64 (2000)
27-33.

7) K. Okamura, T. Shimoo and T. Seguchi: New Ceramics 11 (1995)1-6.

8) P. G. Partridge and C. M. Ward-Close: Int. Mater. Rev. 38 (1994) 1-24.

9) H. E. Deve: Metall. Mater. Trans. A 30A (1999) 2513-2522.

10) O. Miyakawa: Metallic Materials Engineering, (Morikita Shuppan, Tokyo, 1997) pp. 246-249. 